values given to success and failure. Full recovery is not harmful and is given a value of zero (not 100), whereas perioperative death is harmful and is given an arbitrary high value of 100 (not 0$)$

Application of utility theory $\left(\left(U_{q}=\left(1-p_{s}\right) U_{s}\right.\right.$ $\left.\left(p_{s} U_{s}\right)\right)$ now gives a valuation of 25 for one year of life with restricted mobility. By implication doctor A would consider this to be $25^{\circ}{ }_{0}$ as harmful as perioperative death and a single case of perioperative death as harmful as four cases each having a one year prognosis with restricted mobility.

There are two different models which lead to different results. The first is what I call the health model, where good health is given a high value (for example, 100) and death (no health) is given a value of zero. This is the model implicitly used by $\mathrm{Dr}$ Theodossi and others and other workers. The second model is the harm model, as outlined above, in which immediate death is given a high disutility and full recovery (not harmful) has zero disutility.

The application of the health model to doctor A's decisions gives rise to the nonsensical result that complete recovery is worth only one third more than a single year of life with restricted mobility. The harm model, however, gives the quite reasonable, if risk averse, result that perioperative death is four times as bad as a single vear of life with restricted mobility. The only arithmetic difference between these two is the choice of valuations for endpoints of perioperative death and complete recovery.

The health model and the harm model represent different ethical view points about what the purpose of the health service is or should be. Karl Popper has pointed out that such a choice may not be resolved by strictly rational argument but that with this sort of ethical question it is better to think in terms of the reduction of harm (disutility) than in terms of the increase of health (utility). ${ }^{1}$

\section{TIM BENSON}

Abies Informatics Ltd,
London W4 4PH

Popper KR, The open society and its enemies. London:
Routledge and Kegan Paul, 1966:158, 284, 285.

\section{Quetelet index in diagnosis of anorexia nervosa}

SIR,-Professor Derek Llewellyn-Jones and Dr Suzanne F Abraham have reported an interesting application of the body mass index of Quetelet (weight in kilogram divided by height in metres squared) in the diagnosis of anorexia nervosa (16 June, p 1800). The index in their 26 patients ranged from 8 to 14 , which in terms of body weight adjusted to a height of $165 \mathrm{~cm}$ is from 22 to $38 \mathrm{~kg}$. It is of interest to estimate the deviations of such low weights from standards of body weight.

The insurance companies produced two standards in 1959 based on average weights and desirable weights. The former tabulates body weight by sex, age, and height but does not distinguish frame size; the latter tabulates ranges of desirable weight by sex, frame size, and height for adults aged 25 and over. According to the most favourable mortality experience of the insurance companies there is no biological need for body weight to increase after adult growth has ceased by around 25. Professor Llewellyn-Jones and Dr Abraham refer to the table of average weights but find its practical application difficult because of its non-availability to general practitioners in Australia. Both tables of average weights and desirable weights are documented in the commonly available Scientific Tables of Geigy. ${ }^{1}$

The table derived from this published materia shows considerable difference between average weight and the lower limit of desirable weight for frame size at a height of $165 \mathrm{~cm}$ for women aged 25-29 years. The reported range of body mass index of anorexia nervosa patients $(<15)$ lies nearer to the deviations derived from the lower limits of desirable weight than from deviations from average. A $20 \%$ deviation from average weight of the 1959 study would tend to overdiagnose anorexia nervosa. The cut off points based on $80^{\circ}$ of the lower limits of desirable body weights for frame size could therefore be of value in diagnosing individual cases of anorexia nervosa. The table of average weights based on the 1959 study is out of date, but the table of desirable weights of the same study has survived the test of time.

Body weights in indoor clothes based on average and desirable standards of insurance companies at height $165 \mathrm{~cm}$ for women aged 25-29 years

\begin{tabular}{lcccc}
\hline & & \multicolumn{3}{c}{$\begin{array}{c}\text { Lower limits } \\
\text { of desirable weight }\end{array}$} \\
\cline { 3 - 5 } Variable & $\begin{array}{c}\text { Average } \\
\text { weight }\end{array}$ & $\begin{array}{c}\text { Small } \\
\text { frame }\end{array}$ & $\begin{array}{c}\text { Medium } \\
\text { frame }\end{array}$ & $\begin{array}{c}\text { Large } \\
\text { frame }\end{array}$ \\
\hline $\begin{array}{c}\text { Weight }(\mathrm{kg}) \\
\text { Body mass index } \\
\left(\frac{\text { weight }}{(1.65)}\right)\end{array}$ & 58.5 & 50.3 & 52.6 & 56.7 \\
$\begin{array}{c}80 \\
\left(1.0 \text { of body }^{\circ}\right. \\
\text { mass index }\end{array}$ & 21.5 & 18.5 & 19.3 & 20.8 \\
\hline
\end{tabular}

All 26 ballet dancers in Professor LlewellynJones and Dr Abraham's study had an index of less than 19. In general ballet dancers are small framed; the lower limit of desirable body mass index (in indoor clothing) for a small framed woman is $18 \cdot 5$. Similarly in our study of the physique of Olympic finalists many of the champion gymnasts were short, light, and very young-for example, Nadia Comaneci: age 15, height $154 \mathrm{~cm}$, weight $40 \mathrm{~kg}$, index $16 \cdot 9 .^{2}$ It appears that ballet dancers and gymnasts have similar physiques. It would be inappropriate to categorise fit gymnasts and ballet dancers who are in their teens as unhealthily underweight on the basis of desirable weights for adults aged 25 and over. Research is needed on the standards of body weights compatible with health and fitness in teenagers.

I am grateful to Dr E C Coles for helpful comments.

Department of Medical Computing

and Statistics,

Welsh National'School of Medicine,

Cardiff $\mathrm{CF} 44 \mathrm{XN}$

' Diem K, Lentner C. Scientific Tables. Documenta Geigy. 7th ed. Basle: Ciba-Geigy, 1972:711-2. Geigy, 7th ed. Basle: Ciba-Geigy, 1972:711-2.
Kosla T, McBroom VC. Physique of female olympic
finalists. Cardiff: Department of Medical Computing and Statistics, Welsh National School of Medicine, 1984:34-5.

** Professor Llewellyn-Jones and Dr Abraham reply below.-ED, $B M \mathcal{H}$.

SIR,-We chose the Quetelet index because it is easy to calculate and because we believe that few general practitioners (in most countries) have access to the average and desirable weight tables.

We would expect that female champion gymnasts and female ballet dancers would have a similar body build and physique (Quetelet index 15-20) and consider both groups to be healthy, although we suspect that female gymnasts, like ballet dancers, are likely to have menstrual disturbances and to express considerable concern about possible weight gain. ${ }^{12}$

We are currently investigating the relation between the Quetelet index "desirable" and standard body weight and skin fold thickness in over 1000 Australian teenagers.

D LLEWELLyN-JONES SuZANNE Abraham

Department of Obstetrics

and Gynaecology,

University of Sydney,

New South

' Abraham SF, Beumont PJV, Fraser IS, Llewellyn-

Jones D. Body weight, exercise and menstrual status amongst ballet dancers in training. Brit $\mathcal{f}$ Obst

Gynae 1982;89:507-10.
Abraham S, Llewellyn-Jones D. Eating disorders-the facts. Oxford: Oxford University Press, 1984 (in press).

\section{Letters from general practitioners to hospitals}

SIR,-A survey of the contents of letters from hospital departments to general practitioners has emphasised shortcomings in their usefulness (16 June, p 1813), which others have confirmed (21 July, p 189). The problem is, however, by no means one sided. We have recently reviewed the drug history in letters from general practitioners for 100 new patients referred to a gastroenterology clinic.

Details of drugs were not mentioned in 36 letters. Five of the patients whose referral letter contained no information did not know the names of their drugs or why they were taking them and did not bring them to the clinic. For the remaining 31 patients we had to rely on their understanding of their treatment. Even when details were given we rarely had a full list of drugs with dosages and the length of time they had been prescribed. Only 13 patients brought their drugs to the clinic for inspection.

An accurate drug history is important for side effects of treatments may have precipitated the referral, particularly to a gastroenterology clinic. Furthermore, only in the light of this information can management be properly planned. We strongly suggest that all letters should contain a full up to date list of drugs and that patients should be encouraged to bring all drugs with them to the clinic.

\section{G K T HOLMES P CRISP \\ D R UPTON}

Derbyshire Royal Infirmary,

Derbyshire Royal
Derby DE1 2QY

SIR,-Over 20 years ago GPs were being criticised about the content and legibility of their referral letters, ${ }^{1}$ and now $\mathrm{Mr}$ William Bado and Dr Christopher J Williams have criticised hospital discharge letters for their lack of detail on social factors and for their delay in reaching the GP (16 June, p 1813).

As a busy teaching hospital unit we were concerned by the problems of communication between hospital doctors and GPs and so reviewed 100 consecutive referral letters concerning acute medical admissions-excluding elective and coronary care unit admissions. The source of the letter (general practitioner, practice partner, or locum) and the time of admission were noted. The content of each letter was assessed on presenting complaint, previous admissions, past medical history, social history, drug history, examination findings, and diagnosis, and an assessment of legibility was made.

Of the 220 patients admitted during the study

period 100 were accompanied by referral letter, of which 48 were written by the patient's GP, 41 by a 